\title{
Experimental Assessment and Thermal Characterization of Ethylene TetraFluoroEthylene ETFE Foil
}

\author{
By Eleni Anastasia Dimitriadou* \\ Andrew Shea ${ }^{\dagger}$
}

\begin{abstract}
Co-polymer facade materials have been a recent and popular option in the building industry as an alternative to glazing. Ethylene TetraFluoroEthylene (ETFE) is a promising case in this category. ETFE has been successfully used in many high-profile projects as an innovative solution to energy-conscious design challenges. In addition, ETFE presents significant savings in cost and structural support requirements, compared with conventional glazing, due to its low weight, and the potential for energy performance benefits due to its relatively high visible light transmittance. There is a lack of detailed published data reporting its thermal behaviour. This study focuses on the examination of heat transfer through the ETFE membrane, surface temperatures, heat losses and solar gains. The paper examines the impact of the material on the overall energy use of a building, as well as thermal comfort and interior conditions. Through field-testing the research will inspect the material's thermal properties to obtain results that will assist in evaluating the suitability of ETFE use in a broader spectrum of building applications. Such an assessment of performance will provide information for further investigation to improve the material's features and optimise energy performance.
\end{abstract}

\section{Introduction}

ETFE is a relatively recent development in the construction industry. Poirazis (2010) and Antretter (2011) reported that there is a gap in the available information concerning the thermal performance of ETFE and, therefore, the potential consequences of its utilization on the overall energy consumption of a building. This research aims to investigate the thermal performance of the material through experimental testing using scale models.

Heat transfer via conduction, convection and radiation contributes to the overall energy performance of ETFE when employed as a façade or roof covering. However, the focus of this study is energy transferred via radiation. Considering their performance towards radiative heat transfer, both glass and

${ }^{*} \mathrm{PhD}$ Candidate, University of Bath, UK.

†Lecturer, University of Bath, UK. 
ETFE foil behave in a similar manner in relation to shortwave radiation; being transmitted, absorbed and reflected, with the absorption of radiation raising the temperature of both the glass and the foil. The two materials behave in a distinctly different manner to each other when subject to long-wave radiation. ETFE is largely transparent to long-wave radiation, in contrast to glass that is opaque to it (Robinson-Gayle et al., 2001). More specifically, in the case of ETFE the largest part of the long-wave radiation will be transmitted, therefore reducing its absorption and re-emission (Poirazis et al., 2010).

The transmission of long-wave radiation in the case of both a glazed and a foil unit will be dependent upon the temperatures of the panes and their surroundings. Depending on the orientation of each material in relation to the temperature difference between the interior and exterior, the occurring longwave radiation flux will be inwards or outwards correspondingly.

\section{Background}

The number of innovations in material technology that occurred over the past century allowed for a quick transmission from one architectural trend to another. ETFE is a good example of the withdrawal from typical forms of building - in this case the typical being float glass - and a tendency towards structural novelty. The purpose of such advance is to lead in return to financial, aesthetic, comfort and safety benefits (LeCuyer et al., 2008).

ETFE is frequently employed as a replacement for glass to decrease the embodied energy and the cost of a transparent structure. In comparison to glazing, ETFE allows for further flexibility in the geometry of a building, as well as reduced fragility, improved weight and behaviour towards light and heat transmission (Brauer, 1999; Robinson-Gayle et al., 2001).

When searching among transparent polymer materials for a replacement to glass, the two most significant properties to be taken into account are the transmittance of solar radiation and long-wave thermal radiation (Yin-ping et al., 1995). However, stability, strength and endurance are also important aspects in the selection process. Thermoplastic polymers other than ETFE, such as polycarbonates including poly ethyl methacrylate (Plexiglas) and polystyrene (Callister et al., 2011) or fluorocarbons including polytetrafluoroethylene (PTFE) and polyethylene (PE) (Minamisawa et al., 2007); have been examined and found unsuitable as a replacement to glazing. Such alternatives have been rejected as they fail to offer a combination of good visual performance, energy transmittance and an adequate engineering material performance (Baille et al., 2006; Callister et al., 2011).

ETFE is typically assembled into cushions of two to five layers and is most commonly used in large installations, e.g. hospitals, shopping malls, atria, exhibition spaces etc. Overall, the use of ETFE has been found to be most suitable where buildings offer a large volume space (Robinson-Gayle et al., 2001). 


\section{Shortwave and Long-wave Radiative Heat Transfer}

Radiation takes place when heat is transmitted in the form of electromagnetic waves through a bounding medium (Ghoshdastidar, 2004). The bounding media through which radiation occurs can be vacuum, gases, or transparent materials (Jones, 2000; Poirazis et al., 2010).

Radiative flux is proportional to the fourth power of the temperature of a body, as originally established by Stefan and Boltzmann and the radiative heat transfer between two surfaces, which is expressed in equation 1 (Ghoshdastidar, 2004).

$$
q_{r}=\sigma \varepsilon A\left(T_{1}^{4}-T_{2}^{4}\right)
$$

Where:

$q_{r}$ : Rate of heat flow by radiation (W)

$\sigma:$ Stefan-Boltzmann constant $\left(5.67 \times 10^{-8} \mathrm{~W} / \mathrm{m}^{2} \mathrm{~K}^{4}\right)$

$\varepsilon$ : Emissivity ( $\varepsilon<1$ for a non-black body)

$A$ : Heat transfer surface area $\left(\mathrm{m}^{2}\right)$

$T_{1}^{4}$ : Absolute surface temperature, surface $1\left({ }^{\circ} \mathrm{K}\right)$

$T_{2}{ }^{4}$ : Absolute ambient surface temperature, surface $2\left({ }^{\circ} \mathrm{K}\right)$

Radiative properties are directly dependent upon direction, wavelength $\lambda$ (m) and temperature $\left({ }^{\circ} \mathrm{K}\right)$ (Modest, 2003). The wavelengths covered by thermal radiation are in the range of 300-50000 $\mathrm{nm}$ (Jones, 2000). Furthermore, the spectral distribution of the thermal radiation that a surface emits depends on the characteristics and the temperature of the surface. The thermal and optical properties of a surface may be altered with the use of a coating application (Poirazis et al., 2010).

\section{Existing Research on ETFE in Relation to Heat Transfer}

Antretter et al. (2008) at the Fraunhofer Institut für Bauphysik, Germany, performed full-scale model tests on a structure covered by an ETFE cushion to validate the results of a computational fluid dynamics (CFD) model used to predict heat distribution under several inclinations. Field tests and computational modelling revealed that membrane cushions present an uneven distribution of heat in their interior (Antretter et al., 2008).

For a temperature difference of $30^{\circ} \mathrm{C}$ it was discovered that $30 \%$ of the total heat flux took place through convection, whereas $70 \%$ took place through radiation. The experiment also demonstrated that the radiative heat flux is not connected to the inclination - it merely depends on the temperature difference, in contrast to convective heat transfer, which increased with a rise of inclination (Antretter et al., 2008). Similarly, the U-value of a multi-foil ETFE assembly is reduced when used in a horizontal position, which is why ETFE is preferably located on roofs instead of walls (Robinson-Gayle et al., 2001). 
Poirazis et al. (2010) performed a study on a summer scenario, wherein heat transfer through ETFE was simulated and a mathematical model developed to determinate the heat transfer for ETFE cushions. They concluded that there was an estimated $12 \%$ increase in heat flux due to long-wave radiation, in comparison to glazing. The increase in heat gain during day time was not found to be significant, in contrast to the heat loss that occurs during night time. The research also indicated a need for the specification of ETFE spectral properties, detailing its transmittance, absorptance and reflectance (Poirazis et al., 2010).

\section{Experimental Set-up}

Two identical boxes were constructed; one covered with ETFE and the other with glass. The walls and floor of the boxes were $100 \mathrm{~mm}$ thick, comprising of two sheets of $50 \mathrm{~mm}$ thick rigid PIR insulation board $(\lambda=0.022$ $\mathrm{W} / \mathrm{mK}$ ). The boxes enclosed a space of $350 \mathrm{~mm}$ height, $300 \mathrm{~mm}$ width and 600 $\mathrm{mm}$ length. The two insulated boxes were placed on the roof of a campus building at the University of Bath. Figures 1-3 present the experimental set-up.

Figure 1. Experimentation Boxes

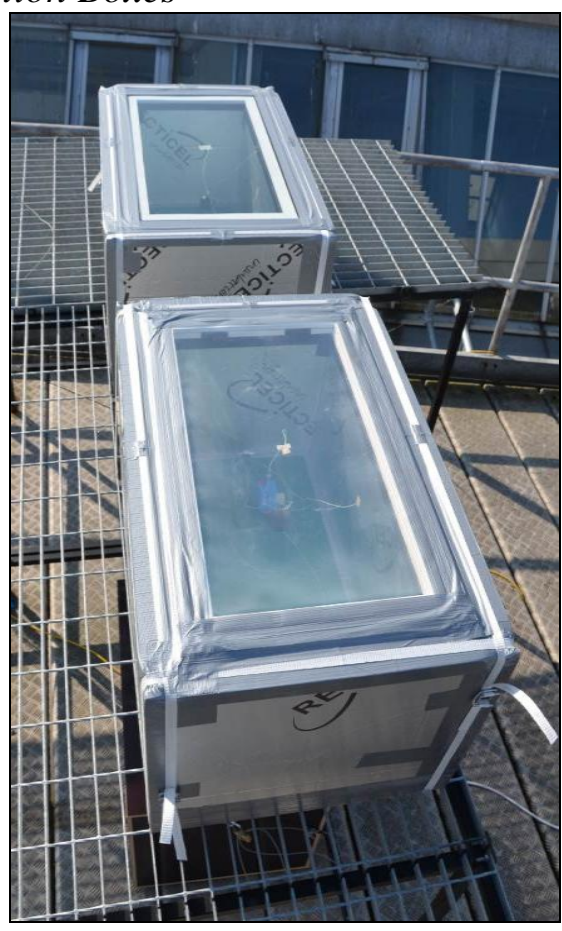


Figure 2. Waterproof Box Containing the Measuring Devices

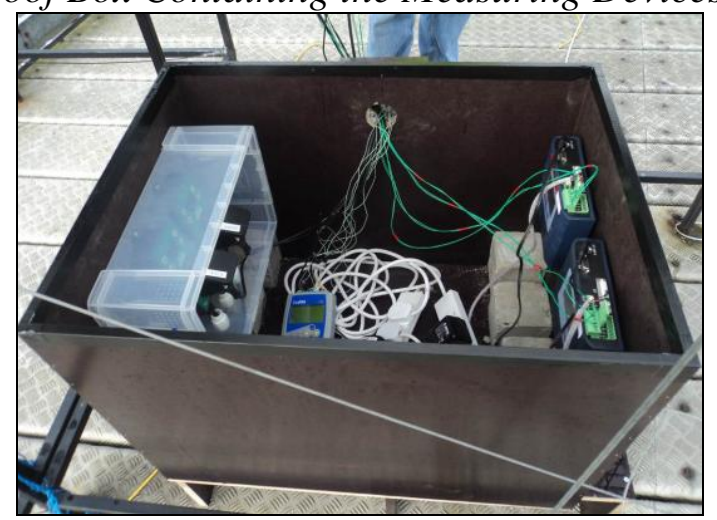

Figure 3. Experimental Set-up on the Roof of the University Building

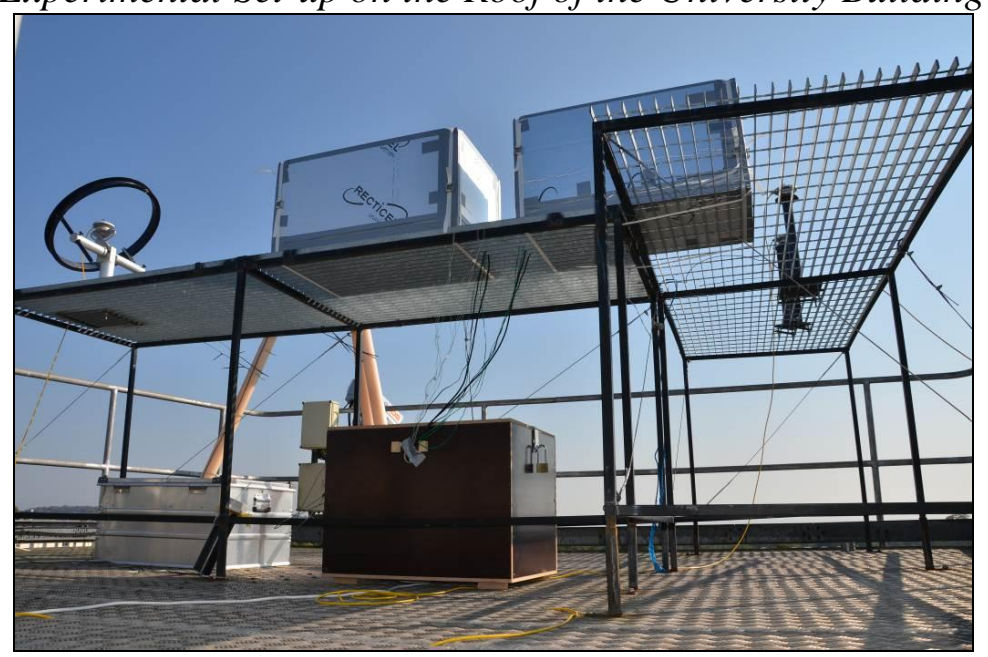

Initially, one box was covered with a single white ETFE foil while the second box was sealed with a single glazed unit of $4 \mathrm{~mm}$ thickness. Measurements were then taken for a period of two weeks, at which point the ETFE foil was substituted. The subsequent experiments took place with the first box being covered by single layers of clear, clear fritted, matt and white fritted ETFE membranes. The glass box maintained the same setup of $4 \mathrm{~mm}$ thick single glazed unit throughout the study period.

A $300 \mathrm{~mm} \times 600 \mathrm{~mm}$ heat mat with a rated power of $32 \mathrm{~W}$ was enclosed within each box. Each heat mat was linked to a thermostat set to a temperature of $20^{\circ} \mathrm{C}$. Whenever the interior air temperature dropped below the set point, the heat mat of the corresponding box generated heat. The energy consumed by each mat was measured using Elster A100c electricity meters. The pulsed output from each meter was recorded using a Grant SQ2010 data logger. The summed total number of pulses was stored at 5 minute intervals and was used to quantify the energy performance of each box subject to the external conditions.

Four K-type thermocouples were attached to the interior of each box to measure surface temperatures within the boxes. Each box was also fitted with 
air temperature and black bulb radiant temperature measuring devices to record internal conditions (Figure 4).

Figure 4. Measuring Devices Location Diagram

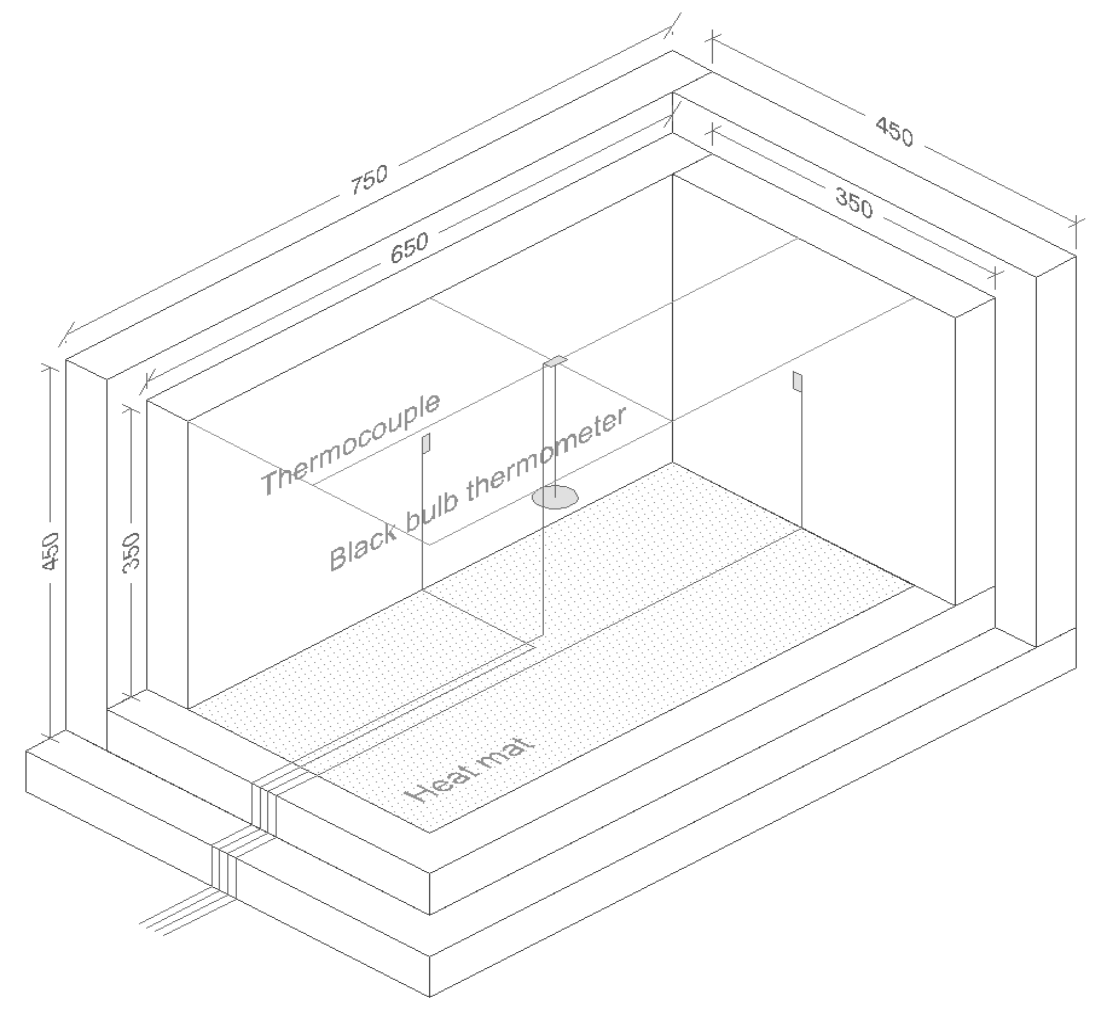

External air temperature was monitored in the same location of the experiment. Additionally, a Kipp \& Zonen CGR3 pyrgeometer and a CMP3 pyranometer were used for the measurement of the corresponding incident long-wave and shortwave radiation.

\section{Results}

The results reported here relate to a single clear foil which was studied alongside a flat single glazed unit (Figure 1). The measurements took place between $11^{\text {th }}$ December 2011 and $25^{\text {th }}$ December 2011. A good variation of weather conditions took place (Figure 5), allowing for a comparison between the function of ETFE membrane and that of glass under a broad spectrum of radiative circumstances. 
Figure 5. External Air Temperature Profile

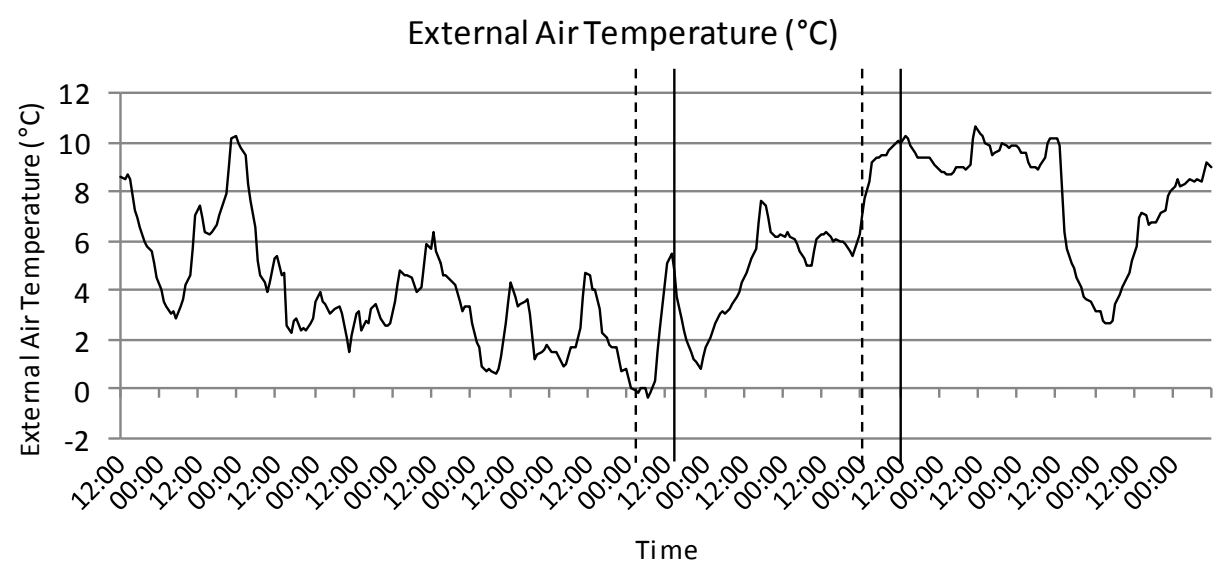

The focus was placed on two distinctive days: one of a clear sky (as indicated on the left set of vertical lines) and one of an overcast sky (as seen on the right), for both day (in dotted lines) and night (solid lines). The clear conditions chosen for detailed analysis occurred on the $18^{\text {th }}$ December 2011 and the overcast conditions on the $21^{\text {st }}$ December 2011. The external air temperature (Figure 5) presented different values during the two dates for both day and night.

The shortwave measurements describe solar radiation and are presented in Figure 6.

Figure 6. Shortwave Radiation $\left(\mathrm{W} / \mathrm{m}^{2}\right)$

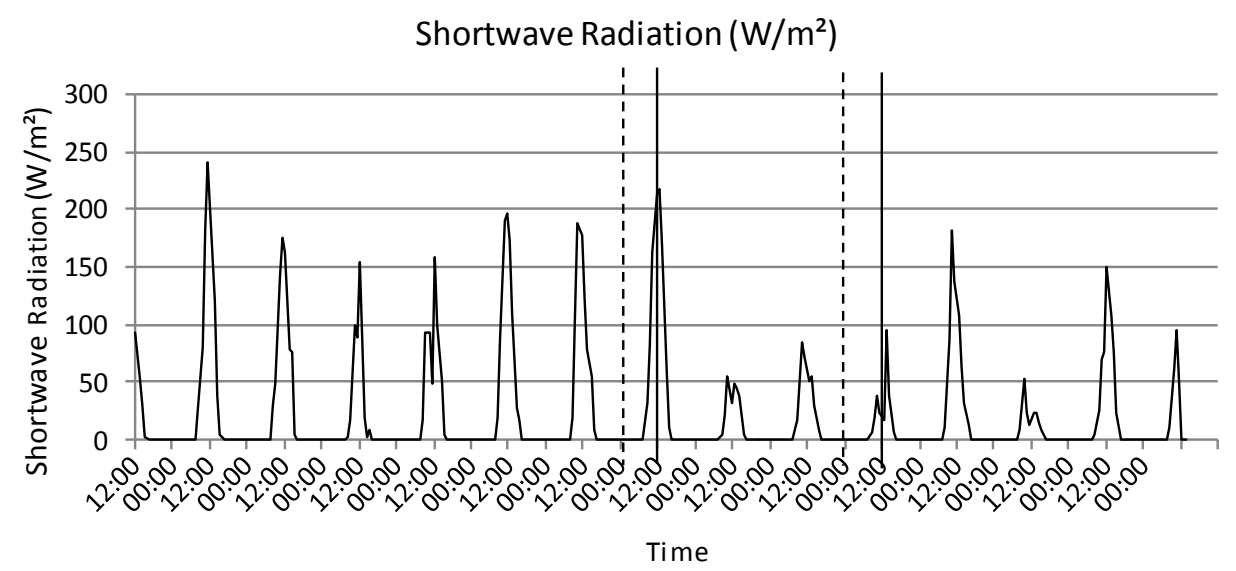

The long-wave measurements (Figure 7) represent net long-wave radiation as measured by the pyrgeometer device. Lower net long-wave values $\approx-150$ $\mathrm{W} / \mathrm{m}^{2}$ indicate a clear sky, whilst values $\approx 0 \mathrm{~W} / \mathrm{m}^{2}$ indicate a fully overcast sky.

Long-wave radiation is significant, as it will indicate the existence or lack of clouds above the cladding material and the environmental measurement equipment. Heat loss through the material will be greater under a clear sky, rather than under a cloudy one (Zhang et al., 1996). Moreover, the importance 
of clouds on sky radiation increases with the drop of temperature, especially during winter (Berdahl et al., 1982). This fact is significant in the case of this experiment as it took place during December, under mostly cloudy conditions, when the solar influence on the passive design aspect of the boxes was at its lowest.

Figure 7. Long-wave Radiation $\left(\mathrm{W} / \mathrm{m}^{2}\right)$

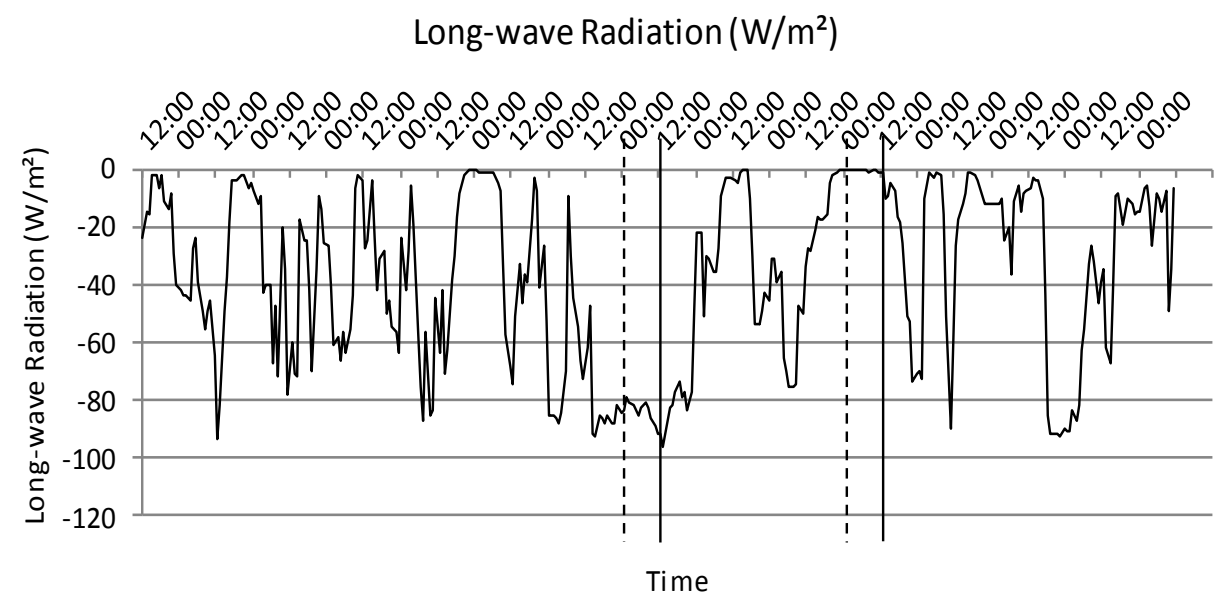

The correlation between low external air temperatures and a clear sky can be noticed between Figure 4, 5 and 6. At the same time, higher external air temperatures are detected under an overcast sky on the same figures.

The results of the overall behaviour of each material as a response to external air temperature, shortwave and long-wave radiation can be summarised on the operative temperature (Figure 8) as it was calculated for each box. The operative temperature combines the measured air temperature and the mean radiant temperature inside each box and is effectively an index of the warmth of the environment (CIBSE, 2001).

Figure 8. Operative Temperature $\left({ }^{\circ} \mathrm{C}\right)$

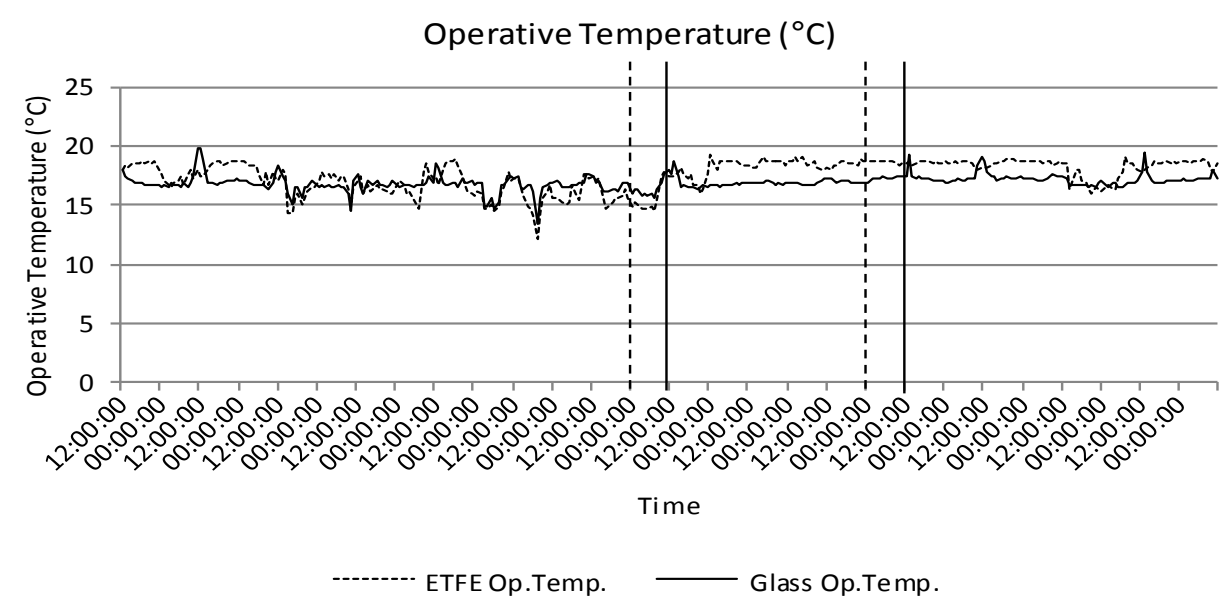


Both materials absorb and trap shortwave solar radiation which causes a rise in the operative temperature during the day, whereas internal conditions reach a cooler temperature during the night. Under clear sky conditions ETFE demonstrates higher operative temperatures than glass during day and lower during night. This is in agreement with the previously mentioned fact that ETFE is transparent to long-wave radiation, therefore losing a significant amount of heat once solar radiation is absent. In conclusion, clear ETFE is less successful than glass in achieving control over comfort conditions under clear sky conditions, for both the case of heating and cooling of a space. However, under the combination of an overcast sky and relatively high external air temperatures, both materials present a steady, satisfactory performance in the attempt to maintain a comfortable interior environment. More specifically, the operative temperature values inside the ETFE box are more consistent and closer to the set point temperature of $20^{\circ} \mathrm{C}$ than those calculated for the glass box, indicating that ETFE is more successful than glass in maintaining the desired environment under overcast sky conditions.

The top surface temperature of glass is consistently higher than that of ETFE, as the material absorbs and retains heat, as it can be seen in Figure 9.

Figure 9. ETFE and Glass Surface Temperature $\left({ }^{\circ} \mathrm{C}\right)$

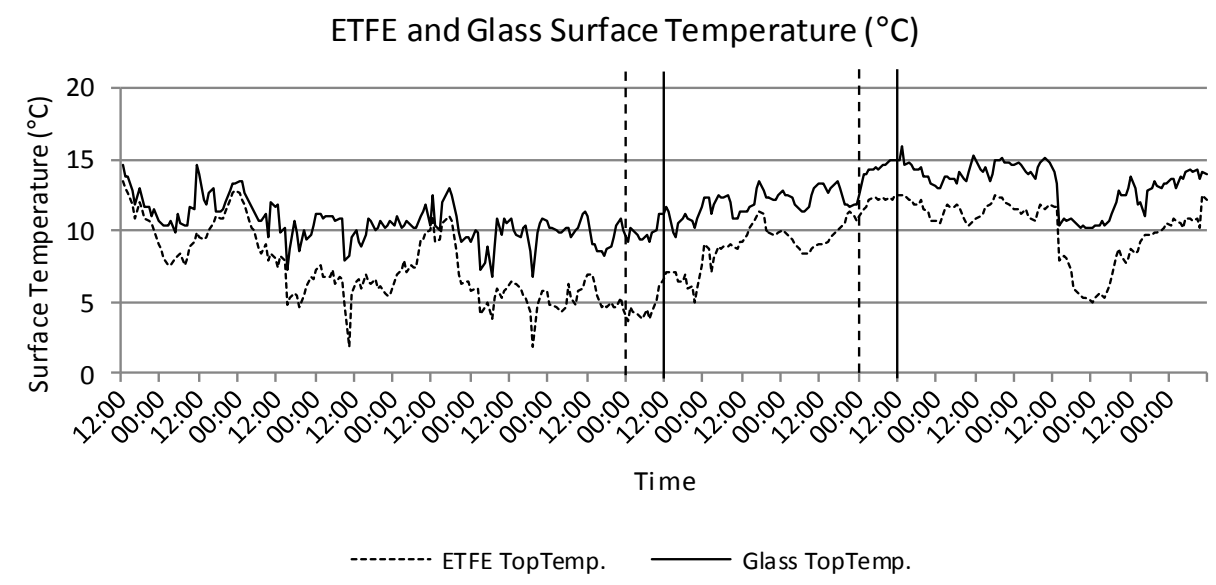

The aforementioned results can be summarized on the energy consumption of each box in the attempt to maintain a steady temperature. Figure 10 depicts the pulse meter recorded in the case of each box as an expression of their distinct thermal response. Each measured pulse represents $1 \mathrm{Wh}$. 
Figure 10. Energy Meter Pulsed Output Record

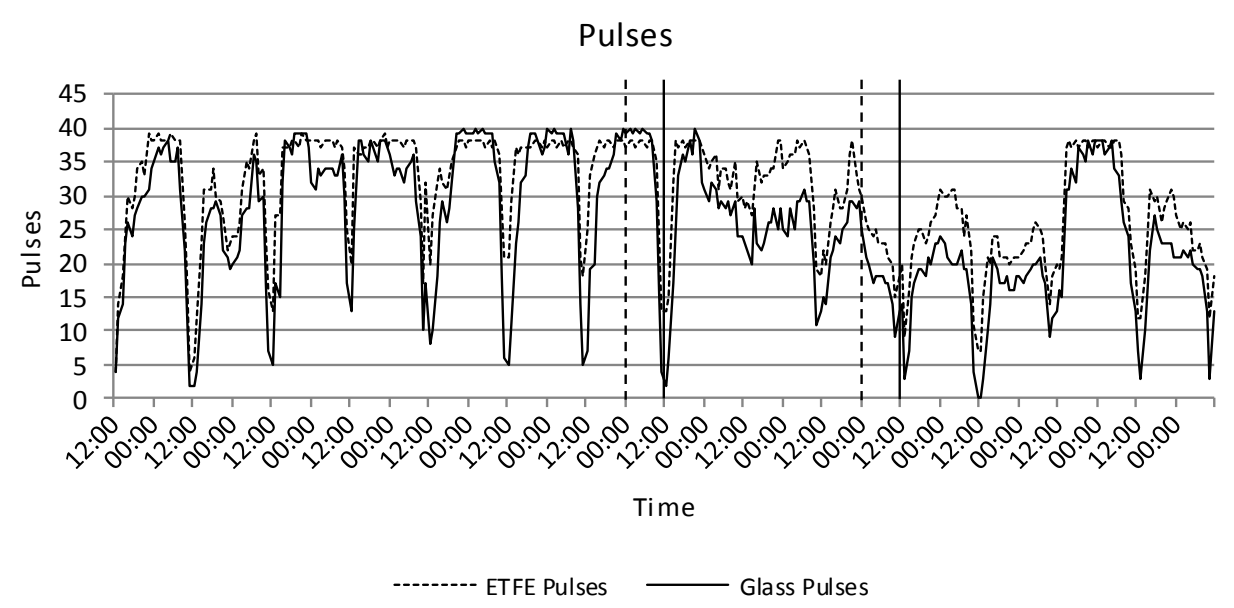

For a total of two weeks of measurements, the clear-ETFE box consumed $2.04 \mathrm{kWh}$ to maintain the desired interior temperature, whereas the glass box used $1.73 \mathrm{kWh}$. This equates to about $18 \%$ higher energy consumption in the case of ETFE over that of glass.

Under cloudy sky conditions, ETFE consistently registered higher energy consumption than the glass, for both day and night-time conditions.

In the form of a single clear layer, ETFE consumes more energy than glass; however, as mentioned earlier in the article, ETFE is hardly ever employed as a single layer but in the form of a cushion of at least two layers. In this case the air trapped inside the cushion works as an insulator and therefore lowers the U-value of the cladding unit. As a result, these results represent the performance of the material itself and not its typical practice of application.

\section{Discussion}

A statistical analysis was performed to examine the results obtained. A model was developed to allow for the estimation of energy consumption for clear ETFE foil and the quantification of its energy performance depending on external air temperature and long-wave radiation.

The mathematical model resulting from this analysis allowed for the estimation of energy consumption as a response to external air temperature and long-wave radiation. Two scenarios were taken into consideration, one for a clear night sky and one for an overcast night sky.

A Kipp \& Zonen CGR 3 Pyrgeometer was employed for the measurement of long-wave radiation. As stated earlier, values for the net long-wave radiation of a clear sky are $L_{n e t} \approx-150 \mathrm{~W} / \mathrm{m}^{2}$ and that of a fully clouded sky as $L_{n e t} \approx 0 \mathrm{~W} / \mathrm{m}^{2}$ (Kipp\&Zonen, 2010). Data recorded during this study covered a range between completely clear and completely overcast and the analysed data 
sets were selected on the criterion of representing a uniform and constant lack or presence of clouds within the ranges measured.

The processed measurements were taken during the night-time period. In the case of the clear sky, external air temperatures were in the range of -0.4 to $2.3^{\circ} \mathrm{C}$ and the long-wave radiation in the range of -79 to $-88.4 \mathrm{~W} / \mathrm{m}^{2}$. The ETFE box energy response was stable; of 37-38 pulses/hour, whereas the glass box responded with the variable range of 32-40 pulses/hour (Figure 11).

Figure 11. Clear Night Sky: Energy Consumption in Relation to External Conditions

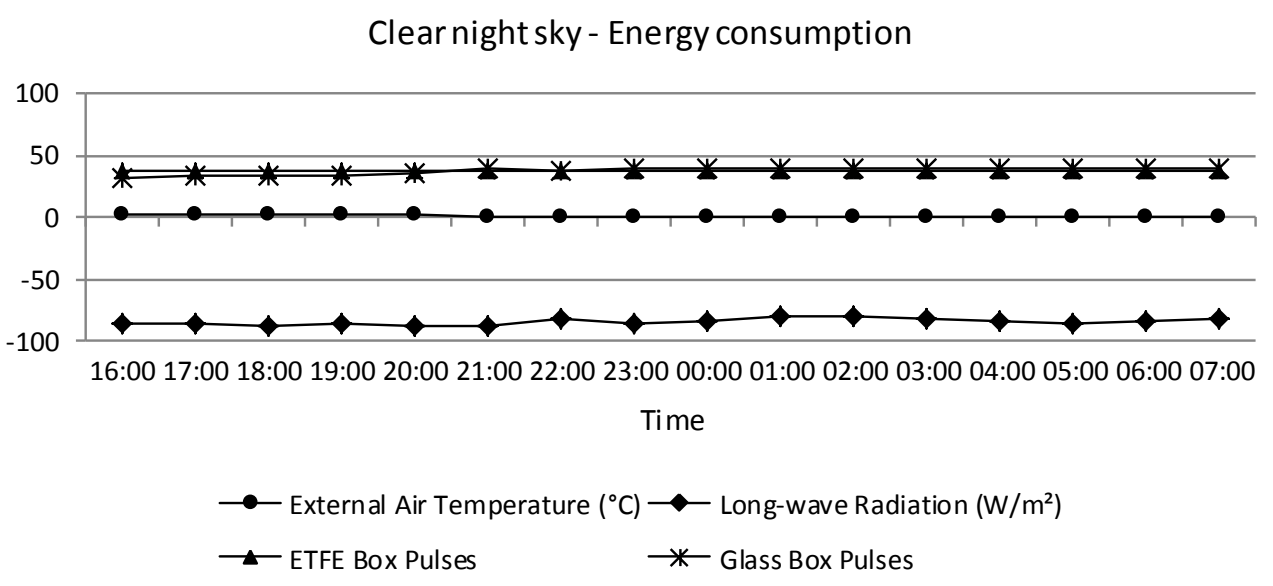

In the case of the overcast sky external air temperatures varied between 5.4 and $9.5^{\circ} \mathrm{C}$; while long-wave radiation values ranged between -0.3 and $17.5 \mathrm{~W} / \mathrm{m}^{2}$. The ETFE box energy response presented values of 23-38 pulses/hour, whereas the glass box showed values of 17-29 pulses/hour (Figure 12).

Figure 12. Overcast Night Sky: Energy Consumption in Relation to External Conditions

Overcast night sky - Energy consumption

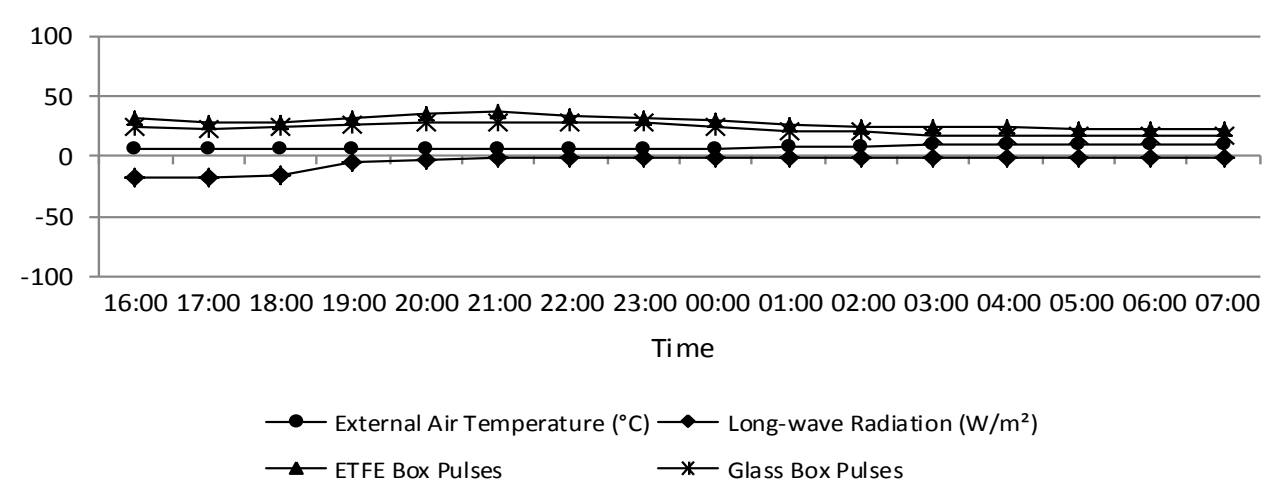




\section{Conclusions and Further Work}

Energy consumption proved to be dependent on external air temperature and long-wave radiation. In the case of lower external air temperature, energy consumption rose in response. The same happened for a drop in long-wave radiation, i.e. the energy consumption of both boxes was noticeably higher in the absence of clouds and lower in their presence; with glass demonstrating a better performance than ETFE in both cases.

The resulting model presented a satisfactory level of correlation for an overcast sky: $\mathrm{R}^{2}$ varying from 0.886 to 0.957 ; but a less satisfactory one for a clear sky: $\mathrm{R}^{2}$ between 0.028 and 0.820 . Figures 13 and 14 demonstrate a summary of the measured and predicted pulses for ETFE and glass correspondingly, as the result of the mathematical model. Some condensation was observed on the underside (i.e. interior) of both glass and ETFE. As the ETFE surface had a consistently lower temperature than the glass one, ETFE gathered more condensation and the resulting latent heat effects are likely to be responsible for the poor correlation coefficient for the clear sky model, which will be addressed in future experimental design and analysis.

Figure 13. Measured and Predicted Pulses for ETFE

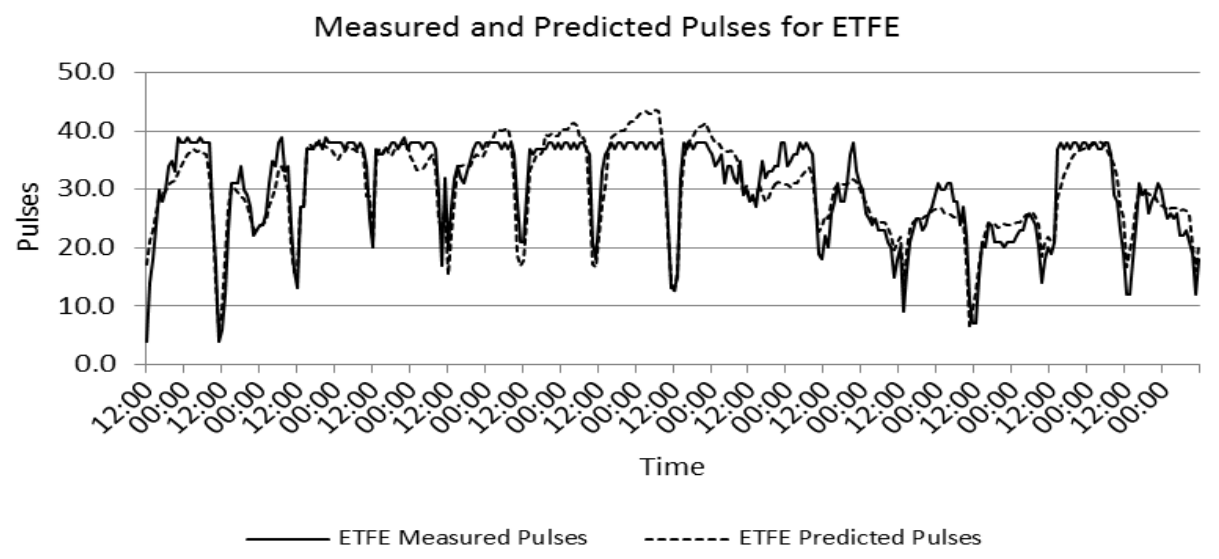

Figure 14. Measured and Predicted Pulses for Glass

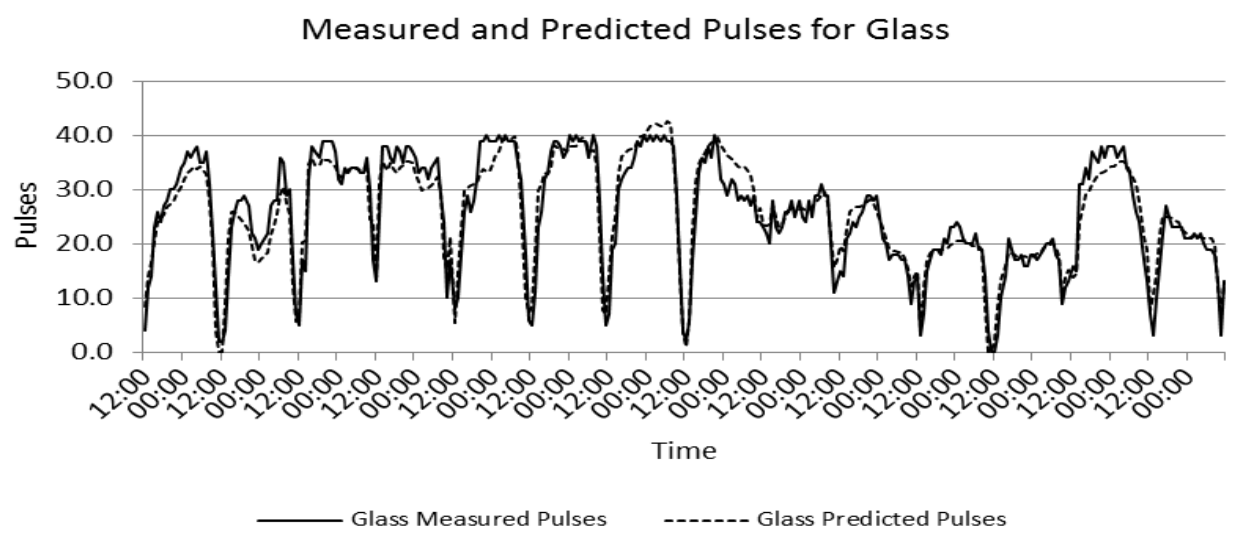


The conducted experiments will be refined and repeated. The subsequent set of experiments will be performed at a larger scale and on an inflated cushion in comparison to a double glazed unit. In that case the results will be closer to realistic conditions, since that is the way ETFE is typically assembled. After the conduction of the new experiment, another statistical analysis will follow leading to a simple model to estimate the amount of heat transfer through the material for each case of all 5 types of ETFE foil.

\section{References}

Antretter, F., W. Haupt \& A. Holm (2008). Thermal Transfer through Membrane Cushions Analyzed by Computational Fluid Dynamics. 8th Nordic Symposium on Building Physics in the Nordic Countries. Copenhagen, Lyngby: 347-354.

Baille, A., J. C. López, S. Bonachela, M. M. González-Real \& J. I. Montero (2006). "Night energy balance in a heated low-cost plastic greenhouse." Agricultural and Forest Meteorology 137(1-2): 107-118.

Berdahl, P. \& R. Fromberg (1982). "The thermal radiance of clear skies." Solar Energy 29(4): 299-314.

Brauer, G. (1999). "Large area glass coating." Surface \& Coatings Technology 112(1-3): 358-365.

Callister, W. \& D. Rethwisch (2011). Materials science and engineering, John Wiley.

CIBSE (2001). CIBSE Guide C3. Heat Transfer. United Kingdom, Butterworth-Heinemann: 328.

Ghoshdastidar, P. S. (2004). Heat transfer. New Delhi; Oxford Oxford University Press.

Jones, H. (2000). Radiation Heat Transfer, Oxford University Press.

Kipp \& Zonen (2010). CGR 3 Pyrgeometer Instruction Sheet. Delft.

LeCuyer, A., I. Liddell, S. Lehnert \& B. Morris (2008). ETFE, Technology and Design. Basel, Switzerland, Birkhauser Verlag AG.

Minamisawa, R. A., V. Abidzina, A. d. Almeida, S. Budak, I. Tereshko, I. Elkin \& D. Ila (2007). "Radiation effects on ETFE polymer exposed to glow discharge." Nuclear Instruments and Methods in Physics Research(B 261): 715-718.

Modest, M. (2003). Radiative Heat Transfer. Amsterdam ; Boston, Academic Press.

Poirazis, H., M. Kragh \& C. Hogg (2010). Energy modelling of ETFE membranes in building applications - Gathering material properties. XI International IBPSA Conference. Glasgow, ARUP.

Robinson-Gayle, S., M. Kolokotroni, A. Cripps \& S. Tanno (2001). "ETFE foil cushions in roofs and atria." Construction and Building Materials 15(7): 323-327. 
Yin-ping, Z. \& G. Xin-shi (1995). "A new method for determination of the optical constants and thermal radiation properties of semi-transparent films." Solar Energy Materials and Solar Cells 37(3-4): 379-387.

Zhang, Y., L. Gauthier, D. de Halleux, B. Dansereau \& A. Gosselin (1996). "Effect of covering materials on energy consumption and greenhouse microclimate." Agricultural and Forest Meteorology 82(1-4): 227-244. 